\title{
Isolation and characterization of bacteria associated with dental caries with special reference to their etiologic potential
}

\author{
Abdul Arif Khan ${ }^{1 *}$, Sudhir Kumar Jain ${ }^{2}$, Archana Shrivastav ${ }^{3}$ \\ ${ }^{1}$ Dep. of Microbiology, College of Life Sciences, Cancer Hospital \& Research Institute, Gwalior (MP) 474009 India \\ ${ }^{2}$ School of Studies in Microbiology, Vikram University, Ujjain (MP) 456010 India \\ *Corresponding Author: arif1981@ rediffmail.com, Tel.: +91-94065-00814
}

Available online at: www.isroset.org

Accepted: 15/Aug/2018, Online: 30/Aug/ 2018

\begin{abstract}
The dental caries is a significant public health problem affecting a number of children and adults throughout the globe. However, the prevalence of dental caries is increasing with increasing consumption of dietary sugar but several factors other than sugar are suggested for the etiology of dental caries including involvement of microorganisms and host factors. The microbes involved in dental caries convert dietary sugar into acid which lead to demineralization of tooth enamel and ultimately results in development of dental caries. The mutans streptococci including S. mutans are suggested to be involved in the etiology of dental caries. Under certain circumstances dental caries can develop even in the absence of these organisms. Due to the disparity in the etiology of this disease, we designed the study to isolate microbes from dental caries and compared them with microbes isolated from healthy individuals. The results revealed that although mutans streptococci is a major contributor in the etiology of dental caries, but some other non-mutans organisms can also contribute to dental caries etiology. The results suggest that proper consideration for removal of non mutans cariogenic bacteria should be given in addition to removal of mutans streptococci for management of dental caries. The results also suggest that some future studies focusing on removal of non mutans organism, mutans streptococci and both kind of organisms and their subsequent effects on management of dental caries should be done in order to understand relative contribution of these organisms in disease etiology.
\end{abstract}

Keywords-Dental caries, sugar, microbes, Streptococcus, dental plaque

\section{INTRODUCTION}

Dental caries is generally considered as chronic disease and has multifactorial etiology with the involvement of plaque, microbes and consumption of sugar [1]. It is the most common reason for tooth loss in the United States. An average American loose 5 teeth and get caries attack in 11 more teeth by the age of 35 [2]. The prevalence of dental caries is increasing in Asian countries including India. As per the information given by National Oral Health Survey (2004), the prevalence of dental caries is $63.1 \%, 53.8 \%$, and $51.9 \%$ in 15,12 , and 5 years children respectively in different geographic locations of India. The prevalence is also varied by different geographic locations and present different pictures related to caries prevalence [3]. The change in dietary habits in developing country like India is also suggested to play an important role in increased prevalence of dental caries with increased consumption of sugar. It is suggested that ability of sugar to cause dental caries is associated with concentration and frequency of sugar consumption [4, 5]. Microorganisms usually form biofilm on tooth surface, which is an adherent population of microbes made of cells, extracellular matrix and water [6]. The signalling between different microbes in a biofilm is maintained through certain quorum sensing mechanisms and therefore the biofilm works in coordination to get functionally effective biofilm and Streptococcus mutans also contribute in this process [7]. S. mutans is generally considered as main cariogenic organisms, but it is working with several other bacteria to form dental biofilm and contribute to dental caries etiology [8]. A long time ago, it has been proposed during 1960 that dental caries is infectious and can be transmitted. The mutans Streptococci was suggested to be the main etiologic reason behind this condition [9]. A strong correlation between level of mutans Streptococci colonization and dental caries was suggested in several studies, however several organisms other than mutans Streptococci were also found to be associated with dental caries in several other studies [10]. With the technological advancement in the identification of microflora associated with dental caries, several progresses have been made in determining molecular mechanisms behind dental caries. The acidogenic microbes coupled with suger in diet and host factors are thought to develop this disease [11]. Despite these understanding behind dental caries etiology several issues have not yet been addressed. For example: the microflora composition associated with dental caries is diverse and it is likely that we have not yet identified all the organisms 
involved in dental caries. Such information about dental caries also requires traditional method to determine respective composition of microbes associated with dental caries in order to understand the role of individual microbe in disease pathogenesis. Therefore we designed this study to identify microbes associated with dental caries. Our aim was to identify the role of mutans Streptococci in the etiology of dental caries in a specific geographic location. In addition the role of other non mutans Streptococci microbes were also evaluated for understanding respective contribution of microbes associated with dental caries.

\section{MethodOLOGY}

\section{Samples collection}

The dental caries samples were collected from different patients attending dental hospitals in Gwalior region. Samples from total 104 dental caries patients were collected while 50 samples were collected from subjects with no clinical suymptoms of dental caries or other oral diseases and used as control. The samples from occlusal pits and fissure caries and smooth surface caries were collected with the help of excavator by dentists. For the collection of root caries, the care was taken to avoid contamination by gingival flora.

\section{Growth media for bacteria isolation}

No transport media was used and samples were immediately processed in lab within 30 minutes. The samples were diluted ten fold in phosphate buffer saline and inoculated on Mitis Salivarius Agar supplimented with $1 \%$ potessium tellurite (HiMedia, Mumbai) and Brain Heart Infusion Agar (HiMedia) using sterile cotton swab. The Plates were incubated at $37^{\circ} \mathrm{C}$ for 48 hours.

\section{Identification of isolated bacteria}

\section{Morphological characterization of bacteria}

The bacteria were gram stained and observed under microscope. The isolated bacteria were first grouped on the basis of Gram staining. The bacterial cells with cocci, bacilli, irregular, single, paired, chain or clusters shapes were found.

\section{Biochemical Characteriation}

The Gram positive cocci were first characterized by catalase test in order to differentiate between Staphylocci and micrococci (catalase positive) from Streptococci and Enterococci (catalase negative). The Streptococci were further characterized with the help of oral streptococci identification manuals [12]. Staphylococci were identified using coagulase test and growth on Manitol Salt Agar. Gram positive bacilli were identified with the help of spore staining followed by sugar fermentation. Irregular non sporing gram positive rods were maintained on actinomyces agar (HiMedia) and identified by their branched filamentous appearance with catalase negative, microaerophilic and slow growth and peculiar colony morphology. The probabilistic identification of bacteria software (PIBWin) was used to identify gram negative bacilli. The tests were performed as per the information given in microbiology manual [13]. The yeast were differentiated from bacteria by microscopic examination.

\section{RESULTS AND DISCUSSION}

\section{Isolation of bacteria from patients}

Total 392 bacterial isolates were obtained from processing of 104 dental caries and 50 control samples. Table 1 represent a comparison between isolation of bacteria from dental caries and control group.

\section{Characterization of bacteria isolated from dental caries and control group}

Table 2 presents types of bacteria isolated from dental caries and control group patients. The number of samples showing positive isolation of bacteria and their percentage contribution in each group is also mentioned in given table. Figure 1 represents the screen shot of PIB Win and its use for characterization of bacteria.

\section{Discussion}

WHO has declared that decreased oral health impact overall health of an individual and dental caries is an important contributor for poor oral health throughout the world [14-16]. The role of bacteria in dental caries etiology is already evident, and $S$. mutans is considered as an important organisms involved in dental caries. However, the etiology of dental caries is still disputed due to development of dental caries even in the absence of $S$. mutans [17]. Sometimes mutans Streptococci cannot explain occurrence of caries in certain population $[18,19]$. Therefore, there is continuous controversy regarding involvement of bacteria in the etiology of dental caries. We tried to isolate the organisms associated with dental caries in order to understand etiology of this disease. We isolated total 392 bacteria from both patient and control group. Among which, total 294 organisms were isolated from 104 dental caries patient's samples and 98 organisms were isolated from 50 control group samples. The highest number of streptococci was isolated; total $09(18 \%)$ $S$. mutans was isolated from control group while the 49 $(47.1 \%)$ S. mutans was isolated from dental caries patients. Similarly the percentage of $S$. sobrinus isolation was also higher with dental caries patients in comparison to control group. We observed $8 \%$ S. sobrinus from control group, while $18.26 \%$ S. sobrinus was isolated from dental caries subjects. The percentage isolation of $S$. mitis was also increased in dental caries patients. The control group showed $8 \%$ S. mitis, while the dental caries patients were found to have $19.23 \%$ isolation of $S$. mitis. The number of $S$. sanguis and $S$. salivarius was just slightly increased in dental caries subjects in comparison to control group. Beside above stated 
bacteria, we observed 06 (12\%) S. gordonii from control group while $13(12.5 \%)$ S. gordonii from dental caries patients. S. oralis was isolated from $18 \%$ control group patients and $24.03 \%$ dental caries patients.

While isolating dental caries associated bacteria, we also observed few Staphylococcus aureus. However the percentage isolation of $S$. aureus was very low in both control and dental caries group, but it slightly increased in dental caries subjects in comparison to control group. The $4 \%$ S. aureus was isolated from control group, while this percentage in dental caries group was $7.69 \%$. It might be due to poor oral hygiene in dental caries subjects, which allow the growth of variety of bacteria in oral cavity.

Due to previously validated role of Lactobacilli in dental caries causation, we also isolated Lactobacilli spp. We found that the percentage of Lactobacilli is higher in both control and normal group but this percentage is increased in dental caries group. The percentage of Lactobacilli in control group was found to be $42 \%$ while in dental caries subjects it was $56.73 \%$. So it is also strengthening the previously known role of mutans streptococci and Lactobacilli in the etiology of dental caries. Beside above described organisms, we also observed Pseudomonas aeruginosa, Yeast and Actinomyces spp. from few samples of both control and dental caries subjects (Table 2).

Formation of dental plaque and dental caries is a sequential event leading to structurally and functionally diverse specific microbial community at every step. Many studies have indicated that dental caries is associated with increase in the number of acidogenic, and aciduric (acid tolerating) bacteria in the mouth specifically mutans streptococci and Lactobacilli. Both these bacteria have ability to demineralize tooth enamel contributing to dental caries [20-22]. These bacteria are involved in metabolizing dietary sugar to acid and create low $\mathrm{pH}$ environment at dental surface. In addition, these bacteria are also able to survive and replicate at acidic environment while the bacteria involved in health of tooth enamel are generally sensitive to acidic environment [23].

However in this study we have found many mutans streptococci from healthy patients, while many dental caries samples were found without the growth of mutans streptococci. In has been already investigated in several studies that mutans streptococci are involved in dental caries etiology without any unique association. Even under certain circumstances the mutans streptococci can persist in oral cavity without initiating any dental caries or demineralization of tooth enamel [23, 24]. In contrast, under such circumstances some acidogenic non-mutans streptococci can be involved in the disease [21, 25]. In addition, yeast like Candida spp. are also able to penetrate tooth enamel thereby contribute to development of dental caries, however the role of yeast in development of dental caries is underscored after the discovery of mutans streptococci in etiology of dental caries [26]. We have isolated yeast from dental caries patient samples, therefore it can be assumed that although the role of $S$. mutans and other mutans streptococci is important in dental caries, but the role of other non mutans organisms cannot be underestimated in the etiology of dental caries.

The dental caries associated organisms can be divided in highly carious and least carious organisms. Although, highly carious organisms alone can produce sufficient acid required for demineralization of tooth enamel, but the least carious organisms can also produce the same situation as a whole, even in the absence of highly cariogenic organisms. This was assumed from present study because we identified many samples of dental caries without $S$. mutans, similarly many $S$. mutans was isolated from healthy subjects. So there should be disturbance in balance of acidogenic and alkali producer bacteria in mouth in order to induce dental caries. This disease will happen when both the acidogenic organisms will increase in mouth, while the counteracting alkali producing organisms will decrease.

The complex architecture of microbial community also support the role of non mutans streptococci in addition to mutans streptococci in the etiology of dental caries, As far as the infectivity and development of dental caries by mutans streptococci suggested by Clarke is concerned, it may be due to the fact that Streptococci makes a major share in dental plaque and $S$. mutans has good potential to produce sufficient acid for demineralization of tooth enamel leading to dental caries. However, under some other conditions, many nonmutans organisms as a whole can produce sufficient acid for demineralization of tooth enamel. So the logical way to deal with dental caries problem can be targeted removal of mutans streotococci, but this cannot be completed until total emphasis will be placed over all other acidogenic and aciduric bacteria.

\section{Conclusion and Future Scope}

However the role of $S$. mutans and other mutans streptococci is obvious in dental caries but the role of other non-mutans streptococci should also be considered for proper management of dental caries. The future studies specifically detecting treatment outcome after removal of mutans, non mutans and both kind of organisms in dental caries can raise new points for management of dental caries. This kind of study requires separate considerations and should be done to find out ways to manage dental caries effectively.

\section{Figures and Tables}


Table 1: Comparison between isolation of bacteria from dental caries and control group

\begin{tabular}{|l|c|c|}
\hline Specification & $\begin{array}{c}\text { Dental } \\
\text { Caries }\end{array}$ & $\begin{array}{c}\text { Control } \\
\text { group }\end{array}$ \\
\hline Positive culture & 104 & 50 \\
\hline Organism isolated & 294 & 98 \\
\hline Isolation rate/sample & 2.82 & 1.96 \\
\hline Sample with single & 11 & 11 \\
organism & 93 & 39 \\
\hline Sample with multiple & 15 & 30 \\
organisms & 61 & 09 \\
2 isolates & 15 & 0 \\
3 isolates & 2 & 0 \\
4 isolates & & $\mathbf{9 8}$ \\
\hline 5 isolates & $\mathbf{2 9 4}$ & \\
\hline \multicolumn{2}{|c|}{ Total } &
\end{tabular}

Table 2: Number of dental caries associated bacteria isolated from patients.

\begin{tabular}{|c|c|c|}
\hline Organisms & $\begin{array}{l}\text { Control } \\
\text { group } \\
(\mathrm{n}=50)\end{array}$ & $\begin{array}{l}\text { Dental } \\
\text { caries } \\
(n=104)\end{array}$ \\
\hline $\begin{array}{l}\text { Gram positive cocci in } \\
\text { chain }\end{array}$ & $09(18 \%)$ & 49 \\
\hline Streptococcus & $04(8 \%)$ & $(47.18 \%)$ \\
\hline mutans & $15(30 \%)$ & $19(18.26 \%)$ \\
\hline S. sobrinus & $08(16 \%)$ & $32(32.69 \%)$ \\
\hline S. sanguis & $12(24 \%)$ & $20(19.23 \%)$ \\
\hline S. mitis & $06(12 \%)$ & $35(33.65 \%)$ \\
\hline S. salivarius & $09(18 \%)$ & $13(12.5 \%)$ \\
\hline $\begin{array}{l}\text { S. gordonii } \\
\text { S. oralis }\end{array}$ & & $25(24.03 \%)$ \\
\hline $\begin{array}{l}\text { Gram positive cocci in } \\
\text { cluster } \\
\quad \text { Staphylococcus } \\
\text { aureus }\end{array}$ & $02(4 \%)$ & $8(7.69 \%)$ \\
\hline $\begin{array}{r}\text { Gram positive bacilli } \\
\text { Lactobacillus spp. }\end{array}$ & $21(42 \%)$ & $59(56.73 \%)$ \\
\hline $\begin{array}{l}\text { Gram positive } \\
\text { irregular filamentous } \\
\text { rod } \\
\quad \text { Actinomyces spp. }\end{array}$ & $02(4 \%)$ & $07(6.73 \%)$ \\
\hline $\begin{array}{c}\text { Gram negative bacilli } \\
\text { P. aeruginosa }\end{array}$ & $05(10 \%)$ & $13(12.5 \%)$ \\
\hline $\begin{array}{l}\text { Eukaryotic cellular } \\
\text { structure } \\
\text { Yeast } \\
\end{array}$ & $05(10 \%)$ & $14(13.46 \%)$ \\
\hline Total Bacteria & $\begin{array}{c}98 \text { out of } 50 \\
\text { samples }\end{array}$ & $\begin{array}{c}294 \text { out of } \\
104 \\
\text { samples } \\
\end{array}$ \\
\hline
\end{tabular}

*percentage (\%) indicates the number of samples having particular organisms

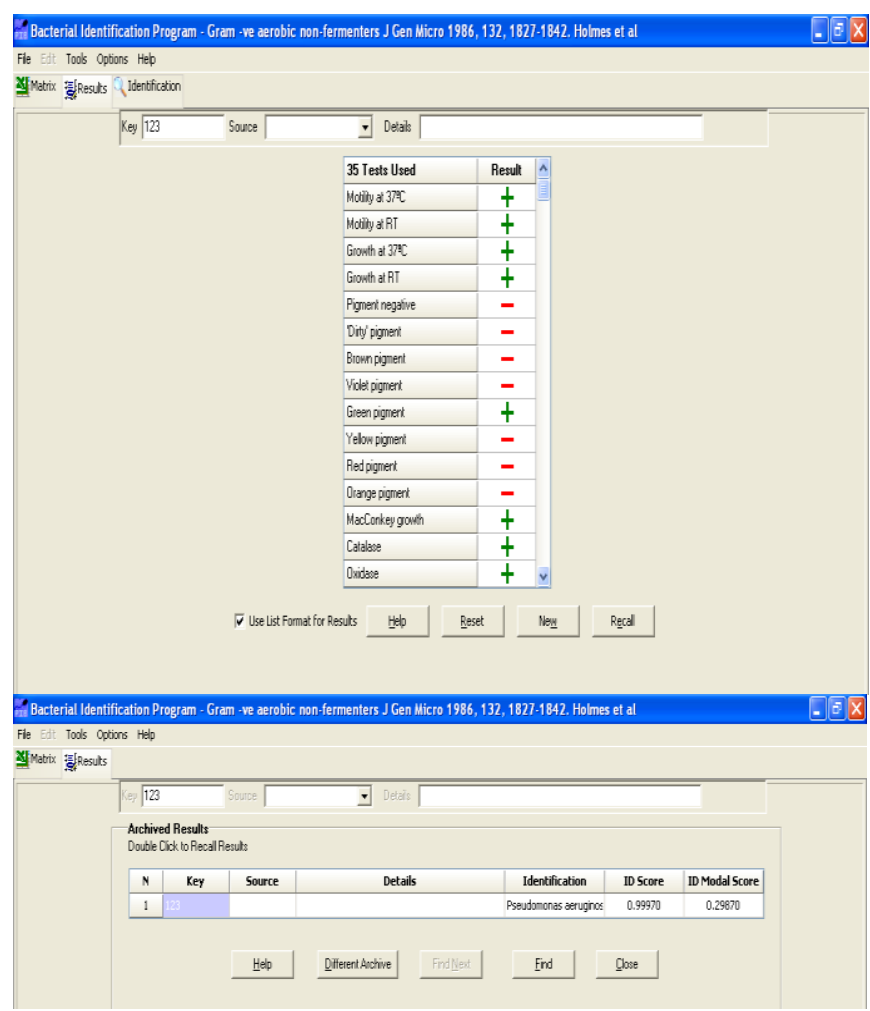

Figure 1: Identification of bacteria through PIBWin

\section{ACKNOWLEDGMENT}

The authors are thankful to related dental surgeons for providing samples for the study.

\section{REFERENCES}

[1] P. Gupta, N. Gupta, A. P. Pawar, S. S. Birajdar, A. S. Natt, H. P. Singh, "Role of sugar and sugar substitutes in dental caries: a review", ISRN Dentistry, Vol.2013, pp.519421, 2013

[2] Committee for a study of public policy options for better dental care, "Chapter 3: Epidemiology and prevention of dental diseases", National Academies Press (US), Washington (DC), 1980

[3] K. Reddy, H. Rapala, B. Kethineni, H. Reddy, A. Reddy and P. Ravindhar, "Prevalence of dental caries in school going children of both urban and rural areas in Mahbubnagar district, Telangana state, (India): An epidemiological study", International Journal of Pedodontic Rehabilitation, Vol.2, Issue.1, pp.7-13, 2017

[4] A. F. Paes Leme, R. Dalcico, C. P. Tabchoury, A. A. Del Bel Cury, P. L. Rosalen and J. A. Cury, "In situ effect of frequent sucrose exposure on enamel demineralization and on plaque composition after APF application and F dentifrice use", Journal of Dental Research, Vol.83, Issue.1, pp.71-5, 2004

[5] C. P. Aires, C. P. Tabchoury, A. A. Del Bel Cury, H. Koo and J. A. Cury, "Effect of sucrose concentration on dental biofilm formed in situ and on enamel demineralization", Caries Research, Vol.40, Issue.1, pp.28-32, 2006

[6] I. W. Sutherland, "The biofilm matrix--an immobilized but dynamic microbial environment", Trends in Microbiology, Vol.9, Issue.5, pp.222-7, 2001

[7] Y. H. Li, P. C. Lau, J. H. Lee, R. P. Ellen and D. G. Cvitkovitch, "Natural genetic transformation of Streptococcus mutans growing 
in biofilms", Journal of Bacteriology, Vol.183, Issue.3, pp.897908, 2001

[8] B. J. Paster, S. K. Boches, J. L. Galvin, R. E. Ericson, C. N. Lau, V. A. Levanos, A. Sahasrabudhe and F. E. Dewhirst, "Bacterial diversity in human subgingival plaque", Journal of Bacteriology, Vol.183, Issue.12, pp.3770-83, 2001

[9] R. J. Gibbons and J. van Houte, "Dental caries", Annual Review of Medicine, Vol.26, pp.121-36, 1975

[10] C. Jing, C. Lei, Z. Xuedong and P. Xian, "[Recent achievements in the microbiological etiology of dental caries]", Hua Xi Kou Qiang Yi Xue Za Zhi, Vol.36, Issue.1, pp.104-108, 2018

[11] I. Struzycka, "The oral microbiome in dental caries", Polish Journal of Microbiology, Vol.63, Issue.2, pp.127-35, 2014

[12] A. L. Coykendall, "Classification and identification of the viridans streptococci", Clinical Microbiology Reviews, Vol. 2, Issue.3, pp.315-28, 1989

[13] K. Sharma, "Manuals for microbiology tools and technique", Anne Book Pubication, New Delhi, 2005

[14] H. Thean, M. L. Wong and H. Koh, "The dental awareness of nursing home staff in Singapore -a pilot study. ", Gerodontology, Vol.24, pp.58-63, 2007

[15] K. Yadav and S. Prakash, "Dental Caries: A Review. ", Asian Journal of Biomed and Pharmaceutical Sciences, Vol.6, pp.1-7, 2016

[16] K. Yadav and S. Prakash, "Dental Caries: A Microbiological Approach", Journal of Clinical Infectious Diseases \& Practice, Vol.2, pp.118, 2017

[17] W. J. Loesche and L. H. Straffon, "Longitudinal investigation of the role of Streptococcus mutans in human fissure decay", Infection \& Immunity, Vol.26, Issue.2, pp.498-507, 1979

[18] M.I.N. Matee, F. H. M. Mikx, J. S. Soet, S. Y. Maselle, J. Graaff, H. W. H. Palenstein Helderman, "Mutans streptococci in cariesactive and caries-free infants in Tanzania", Oral Microbiology and Immunology, Vol.8, Issue.5, pp.322-324, 1993

[19] A.C.B. Silva, J.S. Cruz, F.C. Sampaio and D.A.M. Araújo, "Detection of oral streptococci in dental biofilm from caries-active and caries-free children", Brazilian Journal of Microbiology, Vol.39, pp.648-651, 2008

[20] W. J. Loesche, "Role of Streptococcus mutans in human dental decay", Microbiological Reviews, Vol.50, Issue.4, pp.353-80, 1986

[21] P. D. Marsh, "Microbiologic aspects of dental plaque and dental caries", Dental Clinics of North America, Vol.43, Issue.4, pp.599614, v-vi, 1999

[22] M. R. Becker, B. J. Paster, E. J. Leys, M. L. Moeschberger, S. G. Kenyon, J. L. Galvin, S. K. Boches, F. E. Dewhirst and A. L. Griffen, "Molecular analysis of bacterial species associated with childhood caries", Journal of Clinical Microbiology, Vol.40, Issue.3, pp.1001-9, 2002

[23] P. D. Marsh, "Host defences and microbial homeostasis: Role of microbial interactions", Journal of Dental Research, Vol.68, pp.1567-1575, 1989

[24] G. H. Bowden, J. M. Hardie, A. S. McKee, P. D. Marsh, E. D. Filleeri and G. L. Slack, "The microflora associated with developing carious lesion of the distal surfaces of the upper first premolars in 13-14 years old children ", In the proceeding of Microbial aspects of dental caries conference, Washington, pp.233-241, 1976

[25] C. Sansone, J. Van Houte, K. Joshipura, R. Kent and H. C. Margolis, "The association of mutans streptococci and non-mutans streptococci capable of acidogenesis at a low $\mathrm{pH}$ with dental caries on enamel and root surfaces", Journal of Dental Research, Vol.72, Issue. 2, pp.508-16, 1993

[26] T. Klinke and H. W. Klimm, "Induction of caries-like lesions by Candida albicans in an artificial mouth", International Poster
Journal of Dentistry and Oral Medicine, Vol.5, Issue.4, pp.Poster 200, 2003

\section{AUTHORS PROFILE}

A.A. Khan pursed Ph.D. Microbiology from College of Life Sciences, Cancer Hospital \& Research Institute, under Jiwaji University Gwalior. He also served as Assistant Professor in Department of Microbiology College of Life Sciences, Cancer Hospital \& Research Institute, Gwalior (MP), India. $\mathrm{He}$ is a member of several national and international societies related to microbiology and Life sciences. He has published a number of research papers in reputed international journals. His main research work focuses on clinical microbiology.

S. K. Jain pursed Ph.D. Microbiology from Dr. H.S. Gour University Sagar (MP) India. He is working as Associate Professor in School of Studies in Microbiology, Vikram University, Ujjain (MP), India. He is a member and expert

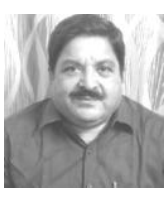
in several national and international associations related to Microbiology and Life sciences. He has published several research papers in reputed national and international journals. His main research work focuses on microbiology, including clinical microbiology, drug discovery, geo microbiology etc. $\mathrm{He}$ has supervised several students ranging from undergraduate to doctorate level.

A. Shrivastav is working as Professor in Department of Microbiology, College of Life Sciences, Cancer Hospital \& Research Institute, Gwalior (MP), India. She is member and expert in several national and international

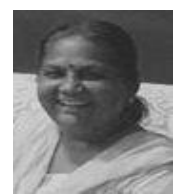
associations related to microbiology and Life sciences. She has supervised a number of doctorate students and published several research papers in reputed national and international journals. Her main research work focuses on microbiology and cancer biology. 